\title{
BIBLIOTECAS PÚBLICAS: O PAPEL DO ESTADO NA CONSTRUÇÃO DE ESPAÇOS DE INFORMAÇÃO E LEITURA
}

Fabiana Sala, Izabele Dias, Silvio César Nunes Militão

Universidade Estadual Paulista - UNESP, Mestrado em Educação, Presidente Prudente, SP. E-mail: fabibuel@gmail.com.

\begin{abstract}
RESUMO
A efetivação de políticas públicas direcionadas às bibliotecas e a difusão da leitura representa a garantia do Estado de Direito ao princípio da igualdade. Este estudo teve como objetivo analisar a situação atual das bibliotecas públicas e o papel do Estado na construção e manutenção de espaços de informação e leitura como direito fundamental à sociedade. A metodologia constou de pesquisa de natureza qualitativa, abrangendo revisão bibliográfica e análise documental sobre a temática em estudo. Os resultados alcançados revelam a falta de políticas informacionais e culturais contínuas para promoção e valorização da biblioteca pública como princípio da democracia. Por fim, pode-se concluir que, somente por meio de mudança política, discursiva e institucional será possível uma transformação bem-sucedida no cenário da biblioteca pública no Brasil.

Palavras-chave: Bibliotecas Públicas; Estado e Políticas Públicas; Políticas informacionais; Políticas culturais; Democratização da informação.

\section{PUBLIC LIBRARIES: THE ROLE OF THE STATE IN THE CONSTRUCTION OF SPACES FOR INFORMATION AND READING}

\begin{abstract}
The implementation of public policies for libraries and dissemination of reading represent the guarantee of the rule of law the principle of equality. This study aimed to analyze the current situation of public libraries and the role of Government in the construction and maintenance of information and reading spaces as a basic right. The methodology consisted of qualitative research, including literature review and analysis of documents on the subject under study. The results achieved reveal the lack of continuous informational and cultural policies for the promotion and enhancement of the public library as a principle of democracy. Finally, it can be concluded that it is through political, discursive and institutional change that it will be possible a successful transformation in the public library scenario in Brazil.
\end{abstract}

Keywords: Public Libraries; State and Public Politics; Information Politics; Cultural Politics; Democratization of Information. 


\section{INTRODUÇÃO}

As políticas públicas informacionais e culturais têm por finalidade a inserção da população carente no universo da cultura, buscando diminuir as desigualdades sociais que o país apresenta. Uma proposta que visa a reversão histórica e social, de restrição do acesso aos bens e serviços culturais limitados a parcelas privilegiadas da população.

Os programas de implementação de bibliotecas públicas e espaços de leitura no país são marcados por descontinuidade, as políticas públicas culturais e informacionais não têm grande impacto nesse campo. No entanto, instituir e promover bibliotecas públicas é fundamental para que se possa democratizar o acesso às fontes de informação e fomentar à leitura.

Entendemos que o papel do Estado é garantir à população direitos fundamentais que lhe permitam viver com dignidade, superando as trevas da ignorância, tendo corpo e mente sãos, amparada pelo acesso ao sistema de saúde e utilizando os bens culturais para que possa desenvolver e apreciar o belo, e integrar-se ao meio social e ambiente e preserva-lo (FERREIRA, 2006, p. 114).

A efetivação de políticas públicas direcionadas às bibliotecas e a difusão da leitura representa a garantia do Estado de Direito ao princípio da igualdade. Este estudo teve como objetivo, analisar a situação das bibliotecas públicas do país e o papel do Estado na construção e manutenção de espaços de informação e leitura como garantia de direito fundamental.

\section{METODOLOGIA}

Em relação aos procedimentos metodológicos visando à coleta e análise de dados, optouse pela pesquisa qualitativa. "A pesquisa qualitativa tem o ambiente natural como sua fonte direta de dados e o pesquisador como seu principal instrumento" (LUDKE; ANDRÉ, 1986, p.11).

Esta pesquisa, teve como propósito, dentro da perspectiva qualitativa, a utilização de diferentes técnicas de pesquisa, a saber:

- Pesquisa bibliográfica: Com o objetivo de realizar um levantamento bibliográfico de autores e obras que tratam do tema em estudo. "A pesquisa bibliográfica é desenvolvida a partir de material já elaborado, constituído principalmente de livros e artigos científicos" (GIL, 2002, p. 44).

- $\quad$ Pesquisa documental: A pesquisa documental se assemelha muito à pesquisa bibliográfica e diferem apenas em relação à natureza das fontes. "A pesquisa documental vale-se de materiais que não receberam ainda um tratamento analítico, ou que ainda podem ser reelaborados de acordo com os objetivos da pesquisa" (GIL, 2002, p. 45). Esta pesquisa comprometeu-se em realizar a consulta e análise de documentos oficiais sobre a temática em estudo.

\section{RESULTADOS DA PESQUISA}

Com o objetivo de identificar o papel do Estado na construção e manutenção de espaços de informação e leitura, foram analisadas as principais políticas e programas informacionais de incentivo à leitura e promoção da biblioteca pública no Brasil, destacando suas principais características e finalidades, conforme segue:

- Instituto Nacional do Livro (INL): Criado em 1937 durante o governo de Getúlio Vargas sob o Regime do Estado Novo com as competências de:

Organizar e publicar a Enciclopédia Brasileira e o Dicionário da Língua Nacional, editar obras de interesse para a cultura nacional, criar bibliotecas públicas e estimular o mercado editorial mediante promoção de medidas 
para aumentar, melhorar e baratear a edição de livros no país (OLIVEIRA,1994, p. 43).

Em 1973 o INL é reestruturado e suas atribuições passam de editor a promotor de publicações de interesse nacional, educacional, científico e cultural. Nesse período, o INL beneficiou prioritariamente a iniciativa privada ao transferir a linha editorial às editoras comerciais. A atuação do INL quanto ao público é polêmica e recebe diversas críticas. No entanto, ao considerar o contexto político, cultural e econômico do período, suas ações tiveram grande contribuição para a promoção da biblioteca e formação de recursos humanos especializados (bibliotecários) no país.

- Leis de Incentivo: Após o período da ditadura, na década de 80, foram empreendidas algumas políticas na área cultural, que "Dispõe sobre benefícios fiscais na área do imposto de renda concedidos a operações de caráter cultural ou artístico" (BRASIL, 2016, p.1), como a Lei no 7.505 criada pelo então presidente José Sarney e posteriormente substituída pela Lei no 8.313, em 1991, criada no Governo Fernando Collor e conhecida como Lei Rouanet que "institui o Programa Nacional de Apoio à Cultura (Pronac)". O Pronac é responsável por captar recursos e incentivos para projetos culturais, que podem ser concedidos por pessoas físicas e jurídicas, as quais se utilizam de abatimentos do imposto de renda (limite de 6\% para pessoa física e $4 \%$ para pessoa jurídica).

- $\quad$ Pró-leitura: Criado em 1992, o projeto faz parte do Acordo de Cooperação BrasilFrança, desenvolvido por inciativas das Secretarias de Educação com a finalidade de instituir uma política nacional de leitura. Visando à formação continuada, o projeto buscava aliar a profissionalização do professor, a pesquisa universitária e prática pedagógica na área da promoção da leitura na escola. Atualmente, o papel do Pró-leitura de manter a formação de alunos professores leitores, está a responsabilidade da Secretaria de Educação Básica.

- Programa Nacional de Incentivo à Leitura (PROLER): O PROLER é um projeto de promoção social da leitura vinculado ao Ministério da Cultura e à Fundação Biblioteca Nacional com o objetivo de contribuir para a expansão do direito à leitura e a promoção das condições de acesso às atividades críticas e criativas de leitura e escrita. O PROLER considera fundamental a articulação da leitura com diferentes expressões culturais, por isso, busca propiciar o acesso à diferentes fontes de informação, construir espaços de leitura e mediar práticas de leitura à processos educacionais. Para um projeto político que tem como meta a formação de leitores, a prática da leitura no ambiente escolar é considerada uma atividade fundamental que possibilita ao leitor avançar para espaços onde a vida social se organiza.

- Programa Nacional Biblioteca na Escola (PNBE): O PNBE, foi instituído no ano de 1997. Uma política governamental que distribuí obras literárias e didáticas às bibliotecas, alunos e professores das escolas públicas da rede de ensino Municipal, Estadual e Federal, no âmbito da educação infantil, ensino médio e educação de jovens e adultos (EJA). O modelo de intervenção adotado pelo PNBE vem, historicamente, privilegiando um único aspecto que compõe uma política de formação de leitores: a compra e a distribuição de livros. No entanto, para que uma política de formação de leitores possa cumprir seu papel de democratizar às fontes de informação e reverter uma tendência histórica de restrição de acesso ao livro como bem cultural privilegiado, sua atuação deve ser encaminhada muito além das ações de compra e distribuição de livros.

- Política Nacional do Livro/Lei no 10.753: Criada em 2003 e também conhecida como Lei do livro, a Lei no 10.753, proposta pelo senador José Sarney, institui-se como instrumento legal e autoriza o Poder Executivo a estabelecer projetos que garantam o acesso ao livro e à leitura. Compreende questões específicas relacionadas à questão do livro, como a instituição de uma política nacional de promoção à leitura, editoração, comercialização e distribuição. 
A Lei do Livro não é algo novo. Entre 1974 e 1976, um grupo de editores e livreiros representando a CBL e o SNEL preparou um anteprojeto da lei, que, quando concluído, foi encaminhado ao ministro da Educação, Ney Braga, durante o governo do presidente Geisel, que não deu a devida importância ao documento (HALLEWELL, 2005, p. 597).

A Lei no 10.753 prevê ainda a construção de linhas de crédito pontuais para o financiamento de editoras e distribuidoras, que se tornam disponíveis a partir do ano de 2005 por meio da intervenção do BNDES (Banco Nacional de Desenvolvimento Econômico e Social), que passa a estabelecer parâmetros e normativas como condições à liberação de crédito para os produtores de livro.

- $\quad$ Fome do Livro: Programa criado em 2004, como resultado dos esforços do governo federal na intenção de instituir uma política pública nacional de promoção ao livro, à leitura e à biblioteca no Brasil. Trata-se de um conjunto variado de ações e projetos instituídos por parte de ministérios; governos estaduais e municipais; organizações privadas e estatais e a sociedade civil que atuaram em diferentes segmentos com a finalidade de implementar a política nacional de leitura e biblioteca.

- Vivaleitura: Lançado em 2004, como o Ano Ibero-Americano do Livro e da Leitura e coordenado pela OEI (Organização dos Estados Ibero-Americanos), Cerlac (Centro Regional para o Fomento do Livro na América Latina e Caribe), UNESCO e os governos dos países participantes, o Vivaleitura foi instituído com a finalidade de propor políticas para promoção do livro e da leitura nos países envolvidos, buscando a reversão dos baixos índices de leitura da população. A partir do ano de 2005, foi criado o Prêmio Vivaleitura, buscando fomentar, estimular e reconhecer as ações relacionadas à leitura. O Prêmio Vivaleitura é uma iniciativa dos Ministérios da Cultura e Educação em parceria com a OEI. São premiadas as melhores experiências que desenvolvam trabalhos relacionados à leitura, de acordo com as seguintes categorias: Biblioteca Viva; Escola Promotora de Leitura; Território da Leitura e; Cidadão Promotor da Leitura. Cada categoria vencedora recebe um prêmio em dinheiro. Além da premiação em dinheiro também é realizada uma menção honrosa José Mindlin, que reconhece as ações que se destacarem por impacto e abrangência.

- $\quad$ Plano Nacional do Livro (PNLL): O PNLL foi criado em 2006 pelos Ministérios da Educação e da Cultura com a finalidade de fomentar e valorizar a leitura, democratizar o acesso e fortalecer o produtor do livro. O PNLL é executado em regime de colaboração entre a União, estados e municípios. O Plano apresenta diretrizes para a construção de uma política pública direcionada à leitura, ao livro, à biblioteca e, em especial, à formação de mediadores, apresentadas no PNLL com instâncias fundamentais para o desenvolvimento social e a promoção da cidadania. Têm como princípio, formar o cidadão leitor, como requisito de inclusão social, garantia de acesso a bens, serviços e cultura. A organização do PNLL é orientada por quatro eixos: 1- Democratização do acesso; 2- Fomento à leitura e à formação de mediadores; 3- Valorização institucional da leitura e incremento de seu valor simbólico e; 4- Desenvolvimento da economia do livro. O PNLL pretende garantir uma política nacional de natureza ampla, capaz de nortear políticas, programas, ações e projetos continuados.

- $\quad$ Programa Mais Cultura: Lançado em 2007, o programa Mais Cultura reconhece a cultura como necessidade fundamental e direito de todos os cidadão brasileiros. O Governo Federal, por meio da criação do programa, incorpora a cultura como veículo essencial no desenvolvimento do país, incluindo-a como uma política estratégica para a redução da desigualdade social. O Mais Cultura busca a inclusão dos segmentos sociais, a valorização do diálogo e da diversidade nos diversos contextos da comunidade, por meio de integração e cooperação de parcerias com ministérios, bancos, organismos internacionais, governos estaduais, municipais e instituições da sociedade civil. 
- Lei 12.244/Universalização das Bibliotecas nas Instituições de Ensino no país: Criada em 2010, a Lei no 12.244 dispõe sobre a universalização das bibliotecas nas instituições de ensino no Brasil. A Lei no 12.244 obriga que todas as instituições de ensino possuam uma biblioteca "As instituições de ensino públicas e privadas de todos os sistemas de ensino do País contarão com bibliotecas, nos termos desta Lei" (BRASIL, 2016, p. 1). A Lei define biblioteca escolar como: "Para os fins desta Lei, considera-se biblioteca escolar a coleção de livros, materiais videográficos e documentos registrados em qualquer suporte destinados a consulta, pesquisa, estudo ou leitura" (BRASIL, 2016, p. 1). No parágrafo único é garantida a manutenção do acervo, o bom funcionamento e o desenvolvimento das coleções da biblioteca escolar.

Após análise das principais políticas e programas informacionais de incentivo à leitura e promoção da biblioteca no país, observa-se que, as políticas públicas informacionais têm sido amplamente discutidas e implementadas, no entanto, precisam ser mais objetivas e pontuais, afim de implementar ações efetivas que possam de fato reverter o quadro atual das bibliotecas públicas no Brasil.

\section{DISCUSSÃO}

É dever do Estado instituir políticas públicas que garantam a promoção da biblioteca pública na sociedade. No entanto, pensar em políticas públicas com essa finalidade, exige pensar o país em sua totalidade, observar suas diversidades e contradições, bem como, exige também, pensar o processo da democracia dos cidadãos brasileiros. O acesso à informação deve ser visto como bem social que garante à população a faculdade de se estabelecer como sujeito.

Consideradas um canal de acesso à informação e ao conhecimento, a instituição das bibliotecas públicas sempre foi almejada pela sociedade, uma vez que, garante à população carente a socialização do livro e demais recursos informacionais, bens que, ainda hoje, são considerados privilégio de poucos.

O acesso à informação ao longo da constituição do Estado brasileiro vem sendo garantido pelas bibliotecas públicas e pelas bibliotecas de instituições públicas. É um direito conquistado nas diversas constituições, consolidado, porém, somente no artigo 5o na Constituição de 1998, quando o país avançou na construção dos direitos sociais exigidos pelo povo Brasileiro após longo período ditatorial (FERREIRA, 2013, p. 2).

Ao instituir políticas públicas, o Estado pretende garantir à sociedade ensejos de existência digna. Portanto, as políticas públicas culturais e informacionais que visam à promoção da biblioteca pública não podem ser vistas como uma política de governo descontínua, mas sim como uma política de Estado, inserida dentro do plano de metas e efetivadas com a disponibilização de recursos suficientes para manter seu funcionamento pleno.

\section{CONCLUSÃO}

As bibliotecas públicas são espaços políticos que possibilitam à sociedade o acesso à informação e ao conhecimento por meio de recursos informacionais disponibilizados pelo Estado. Promover políticas públicas para a construção de redes de bibliotecas públicas em todo o país, é dever do Estado e direito de todo cidadão.

No atual contexto, diversos projetos/programas são implementados com a finalidade de cumprir essa missão. O Estado brasileiro cria diversas políticas que buscam transformar a sociedade em uma sociedade mais crítica e cidadã. No entanto, é necessário enxergar nas bibliotecas um espaço democrático do saber e, reconhecer que a informação e a leitura são instrumentos de formação dos sujeitos. 
Criar e promover bibliotecas públicas por meio de investimento público é o caminho apontado para que a população possa ter, de fato, espaços de informação e leitura capazes de promover à aquisição do conhecimento, com foco no direito fundamental à informação, pois, somente por meio de mudança política, discursiva e institucional será possível uma transformação bem-sucedida no cenário da biblioteca pública no Brasil.

\section{REFERÊNCIAS}

BRASIL. Fundo Nacional de Desenvolvimento da Educação. PNBE. Disponível em: <http://www.fnde.gov.br/programas/biblioteca-da-escola/biblioteca-da-escola-apresentacao>. Acesso em: 3 abr. 2016;

BRASIL. LEI № 12.244 DE 24 DE MAIO DE 2010. Disponível em: <http://www.planalto.gov.br/ccivil_03/_ato2007-2010/2010/lei/l12244.htm>. Acesso em: Acesso em: 25 fev. 2016;

BRASIL. LEI № 8.313, DE 23 DE DEZEMBRO DE 1991. Disponível em: <http://www.planalto.gov.br/ccivil_03/leis/L8313cons.htm>. Acesso em: Acesso em: 25 fev. 2016;

BRASIL. LEI N ${ }^{\circ}$ 7.505, DE 2 DE JULHO DE 1986. Disponível em: <http://www.planalto.gov.br/ccivil_03/leis/L7505.htm>. Acesso em: Acesso em: 25 fev. 2016;

BRASIL. Ministério da Cultura. Fundação Biblioteca Nacional. PROLER: concepção, diretrizes e ações. 2 ed. Rio de Janeiro: 1998;

BRASIL. Ministério da Cultura. Mais Cultura. Disponível em: <http://www.cultura.gov.br/maiscultura>. Acesso em: 3 abr. 2016;

BRASIL. Ministério da Cultura. Plano Nacional do Livro e Leitura: PNLL. Disponível em: <http://www.cultura.gov.br/politicas/livroeleitura/pnll/>. Acesso em: 3 abr. 2016;

FERREIRA, Maria Mary. Biblioteca, leitura e informação no contexto das políticas públicas: um olhar sobre o Brasil da era Lula/Dilma. CTCM: Pernambuco, 2013;

FERREIRA, Maria Mary. Políticas públicas de informação e políticas culturais: e as bibliotecas públicas para onde vão? TransInformação, Campinas, n. 18, maio/ago., 2006.

GIL, Antônio Carlos. Como elaborar projetos de pesquisa. 4. ed. São Paulo: Atlas, 2002;

HALLEWELL, Laurence. O livro no Brasil. 2. ed. São Paulo: Editora da Universidade de São Paulo, 2005;

LUDKE, M.; A N D R É, M. E. D. A. Pesquisa em Educação: abordagens qualitativas. São Paulo: Pedagógica e Universitária, 1986;

OLIVEIRA, Zita Catarina Prates. A biblioteca "fora do tempo": políticas governamentais de bibliotecas públicas no Brasil, 1937-1989. 221 f. Tese (Doutorado em Ciência da Comunicação) Escola de Comunicação e Artes, Universidade de São Paulo, São Paulo, 1994. 